\title{
Sugarcane Cystatin CaneCPI-4 inhibits Melanoma Growth by Angiogenesis Disruption
}

\author{
Juliana P Oliveira', Helena F Magliarelli' ${ }^{1}$, Felipe V Pereira ${ }^{2}$, Andréia Gianotti ${ }^{3}$, Andréa Soares-Costa ${ }^{3}$, Flavio Henrique-Silva ${ }^{3}$, Alda \\ Wakamatsu ${ }^{4}$, Iberê C Soares ${ }^{4}$, Suely Nonogaki ${ }^{5}$, Luiz R Travassos ${ }^{2}$, Adriana K Carmona ${ }^{1}$ and Thaysa Paschoalin ${ }^{2 *}$
}

${ }^{1}$ Departamento de Biofísica, Universidade Federal de São Paulo, São Paulo, Brazil

${ }^{2}$ Departamento de Microbiologia, Imunologia e Parasitologia, Unidade de Oncologia Experimental (UNONEX), Universidade Federal de São Paulo, São Paulo, Brazil ${ }^{3}$ Laboratório de Biologia Molecular, DGE, Universidade Federal de São Carlos, São Paulo, Brazil

${ }^{4}$ LIM14 - Faculdade de Medicina, Universidade de São Paulo, São Paulo, Brazil

5 Instituto Adolfo Lutz, São Paulo, Brazil

\begin{abstract}
Study background: Cathepsins are lysosomal cysteine proteases that have increased expression in tumor cells, may translocate to the cell surface and be secreted. They play a role in tumor angiogenesis. Cystatins are natural cysteine protease inhibitors that can inhibit tumor development, growth and metastasis. In the present work we evaluated the potential therapeutic use of sugarcane cystatin CaneCPI-4 as an anticancer drug.

Methods: Viability, migration, invasion and anchorage-independent growth were investigated in B16F10-Nex2 melanoma and HUVEC cells in the presence of CaneCPI-4. The in vivo effect of CanceCPI-4 on tumor development was assessed using a murine model. Angiogenesis in vitro was evaluated using HUVEC cells plated on Matrigel. Immunohistochemical analysis of CD34 expression in primary melanoma was also carried out.

Results: Sugarcane cystatin CaneCPI-4 was not cytotoxic to melanoma or HUVEC cells growing in vitro, but efficiently inhibited melanoma cell development in vivo. CaneCPI-4 inhibited melanoma and endothelial cell migration and tumor invasion in vitro. Using a Matrigel angiogenesis assay, CaneCPI- 4 at $1 \mu \mathrm{M}$ was able to completely abolished endothelial cell sprouting in vitro. Angiogenesis inhibition was confirmed in vivo by immunohistochemistry.
\end{abstract}

Conclusions: Sugarcane cystatin CaneCPI-4 inhibits melanoma development in vivo by angiogenesis disruption and inhibition of melanoma invasion, migration and anchorage-independent growth.

Keywords: B16F10-Nex2 melanoma cells; Phytocystatins; Cathepsins cysteine proteases; Angiogenesis; Metastasis

\section{Introduction}

Tumorigenesis and metastasis are multistep events in which the overgrowing and invading cancer cells show a number of alterations that allow them to be increasingly self sufficient, promote angiogenesis and invade normal tissues. Tumor angiogenesis or the proliferation of neo-vessels from the pre-existing microvasculature is a prerequisite and a limiting step for tumor growth, restricted by nutrient diffusion in the microenvironment [1]. To expand in size and to metastatize, tumors must induce an "angiogenic switch", changing the local balance in favor of pro-angiogenic rather than anti-angiogenic factors $[2,3]$.

It is well established that a wide variety of proteases are involved in angiogenesis regulation and tumor progression, owing to their ability to degrade components of the extracellular matrix (ECM). Proteolysis can help the cancer cells not only by remodeling the ECM, but also by stimulating tumor growth, invasion and angiogenesis by releasing growth factors which are embedded in the surrounding matrix $[4,5]$. Among the proteases expressed by tumor cells, many studies have reported on the increased expression, activity, cell surface and secreted forms of various cathepsins in human cancers [6].

Upregulation of cathepsins, in several types of cancer, may have diagnostic and prognostic value. Deletion of specific cathepsin genes using mouse cancer models allowed suggestions about their individual roles in cancer progression. In RIP-Tag2 mice, an animal model for pancreatic islet-cell cancer, deletion of cathepsin B or S reduced tumor angiogenesis, whereas cathepsin B- or L-deficient mice showed a decrease in tumor cell proliferation [5]. Kruszewski et al. [7] showed a positive correlation between high levels of cathepsin $\mathrm{B}$ and angiogenesis and, agreeing with this, down regulation of cathepsin B was associated with angiogenesis suppression [8]. In highly metastatic B16F10 murine melanoma, down regulation of cathepsin L impaired cell invasion and migration, using antisense constructs [9]. Similarly, melanoma cells treated with cysteine protease inhibitors (E-64 or chagasin) showed delayed growth in syngeneic mice and increased animal survival [10] Further, the inhibition of cathepsin $\mathrm{K}$ greatly reduced melanoma cell invasion through Matrigel [11].

Assuming that cathepsins among functional cysteine proteases display various activities related to establishment and development of cancer cells, inhibitors of this class of enzymes may have a role in anticancer therapy. Cystatins are natural cysteine protease inhibitors with specific activities. Although the primary function of cystatins

*Corresponding author: Dr. Thaysa Paschoalin, Unidade de Oncologia Experimental, Departamento de Microbiologia, Imunologia e Parasitologia Universidade Federal de São Paulo (UNIFESP), Rua Botucatu, 862, $8^{\circ}$ andar, São Paulo, SP 04023-062, Brazil, Tel: +55-11-5576-4551; Fax: +55-11-5571-5877; E-mail: tpaschoalin@unifesp.br

Received August 09, 2011; Accepted September 07, 2011; Published September 15,2011

Citation: Oliveira JP, Magliarelli HF, Pereira FV, Gianotti A, Soares-Costa A, et al. (2011) Sugarcane Cystatin CaneCPI-4 inhibits Melanoma Growth by Angiogenesis Disruption. J Cancer Sci Ther 3: 161-167. doi:10.4172/1948-5956.1000081

Copyright: @ 2011 Oliveira JP, et al. This is an open-access article distributed under the terms of the Creative Commons Attribution License, which permits unrestricted use, distribution, and reproduction in any medium, provided the original author and source are credited. 
is to limit the cysteine protease activity released from lysosomes and produced during inflammation [12], they may also interfere in tumor development and metastasis [6]. Several studies point to an increased ratio of cathepsin to cystatin in most tumor types compared to normal tissues [13]. Thus, an imbalance in the levels and activity of cathepsins B and L and the levels of cystatins, which are reduced in tumor cells, has been observed [14,15]. Further, Nishikawa et al. [16] detected significantly higher cystatin levels in benign than in malignant ovarian cancers, while no significant difference in serum cathepsin B was observed. Therefore, cystatins could be potential regulators of cathepsin activity of potential therapeutic interest [13].

The inhibitory effect of phytocystatins on human breast cancer invasion has been recently evaluated. Sugarcane cystatin, CaneCPI-4, showed strong inhibitory activity against cathepsins $\mathrm{B}$ and $\mathrm{L}$ and significantly reduced tumor cell invasion on Matrigel in vitro [17]. In the present work, we evaluated the potential therapeutic abilities of sugarcane cystatin CaneCPI-4 in a syngeneic mouse melanoma model. CaneCPI-4 strongly inhibited melanoma development in vivo and was able to decrease angiogenesis in vitro and in vivo. This is the first description of using phytocystatins as therapeutic agents against a melanoma model in vivo.

\section{Materials and Methods}

\section{Mice and cell lineages}

Inbred male C57BL/6 mice, six- to eight-week-old, were purchased from the Center for Development of Experimental Models (CEDEME) animal facility at Federal University of São Paulo (UNIFESP), and were kept in isolators, with autoclaved water and food in spf conditions. The animal experiments were carried out in accordance with the UNIFESP Ethics Committee for Animal Experimentation.

B16F10-Nex2 is a subline derived from B16F10 murine melanoma cells obtained from the Ludwig Institute for Cancer Research (São Paulo Branch), syngeneic to $\mathrm{C} 57 \mathrm{Bl} / 6$ mice. The melanotic subline Nex2 (B16F10-Nex2), isolated at the Experimental Oncology Unit (UNONEX) is characterized by low immunogenicity and moderate aggressiveness. It forms lethal subcutaneous tumors, with no metastasis to the lung unless injected intravenously. Human umbilical vein endothelial cell (HUVEC) line was provided by Julio Scharfstein from Federal University of Rio de Janeiro. Cells were maintained in complete RPMI 1640 medium, pH 7.2, supplemented with $10 \mathrm{mM}$ $\mathrm{N}$-2-hydroxyethylpiperazine-N'-2-ethanesulphonic acid (HEPES), 24 $\mathrm{mM}$ sodium bicarbonate, $10 \%$ heat-inactivated fetal calf serum (FCS) from Gibco (Minneapolis, MN, USA) and $40 \mu \mathrm{g} / \mathrm{mL}$ gentamicin sulfate (Hipolabor Farmacêutica, Sabará, MG, Brazil).

\section{Recombinant sugarcane cystatin}

Recombinant cystatin from sugarcane was produced in Escherichia coli Rosetta (DE3) as described previously $[17,18]$.

\section{In vitro viability assays}

B16F10-Nex2 and HUVEC $\left(5 \times 10^{3}\right.$ cells per well) cells were grown on 96-well plates and incubated for $24 \mathrm{~h}$ with sugarcane cystatins. After cell attachment to plastic, the assay was carried out in the presence of RPMI medium without fetal calf serum (FCS). Alternatively, $10^{3}$ B16F10-Nex 2 cells were cultivated on 96-well plates and incubated for $24 \mathrm{~h}, 48 \mathrm{~h}$ and $72 \mathrm{~h}$ with $1 \mu \mathrm{M}$ of CaneCPI- 4 in the presence of RPMI with $10 \%$ FCS. Cell viability was measured using the Cell Proliferation Kit I (MTT) (Boehringer Mannheim), an MTT-based colorimetric assay for quantification of cell proliferation and viability, following manufacturer's instructions. Readings were performed in a plate reader at $570 \mathrm{~nm}$.

\section{In vitro angiogenesis assay on Matrigel}

In vitro angiogenesis assay on Matrigel was performed as described previously [19]. Briefly, BD Matrigel ${ }^{\mathrm{TM}}$ Matrix (B\&D Biosciences, Bedford, MA, USA) was thawed on ice, distributed in 96-well plates (15 $\mu \mathrm{L}$ per well) and allowed to polymerize for $1 \mathrm{~h}$ at $37^{\circ} \mathrm{C}$. HUVECs (5 $\times 10^{3}$ cells/well) were suspended in $100 \mu \mathrm{L}$ of RPMI medium supplemented with $0.5 \%$ of FCS and added to each well in the presence of recombinant sugarcane cystatin. The plates were incubated at $37^{\circ} \mathrm{C}$ for $18 \mathrm{~h}$ and then images were captured at $8 \mathrm{x}$ magnification with a Sony Cyber-shot camera coupled to a light inverted microscope. The number of pro-angiogenic structures (closed rings arising from dendritic extensions of endothelial cells) was counted from 4 different wells, and the average value was determined for each sample. HUVECs were plated on Matrigel without cystatin, in the control system.

\section{Monolayer wound-healing assay}

HUVEC and B16F10-Nex2 melanoma cells (both $10^{5}$ cells/well) were plated on 12-well plates in triplicates. After cell attachment and growth to a confluent monolayer, the medium was pipetted out, replaced by PBS and one scratch wound was made with a blue P1000 tip (Fisher) in each well. PBS was pipetted out, the serum-free RPMI medium with CaneCPI-4 was added to each well and cells were incubated for $16 \mathrm{~h}$. The plates were observed in a phase contrast microscope and images were captured with a Sony Cyber-shot camera coupled to the light inverted microscope at $0 \mathrm{~h}$ and $16 \mathrm{~h}$. The cell migration distance was determined by measuring the width of the wound and subtracting this value from the initial half-width value of the wound.

\section{Transwell invasion assay}

The Matrigel invasion ability of B16F10-Nex2 melanoma cells pre-incubated with CaneCPI-4 was tested using Biocoat Matrigel Invasion Chambers (B\&D Biosciences, Bedford, MA, USA). Briefly, $56 \mu \mathrm{L}$ of Matrigel diluted (1:12) in cold PBS was added on the upper chambers of 24 -well transwells and incubated for $30 \mathrm{~min}$ at $37^{\circ} \mathrm{C}$ for gel formation. After incubation, $500 \mu \mathrm{L}$ of serum-free RPMI containing $2 \times 10^{5}$ cells pre-incubated or not with sugarcane cystatin was added on the Matrigel-coated PET filters ( 8 - $\mu \mathrm{m}$ pore size). The lower chamber of the transwell unit was filled with $500 \mu \mathrm{L}$ of RPMI supplemented with $10 \%$ FCS, as chemoattractant. Plates were incubated for $24 \mathrm{~h}$ at $37^{\circ} \mathrm{C}$ and then noninvading cells were scraped off on the top of the transwell with a cotton swab. Transwell units were removed from 24-well plates, fixed for 30 min with methanol and stained with Giemsa's stain for 15 min. Invading cells were counted under a light microscope.

\section{Anchorage-independent growth assay}

Base layers $(0.5 \mathrm{~mL})$ of complete RPMI medium containing $0.5 \%$ agar were set on 12-well plates in quadruplicate. The bottom agar was overlaid with $0.5 \mathrm{~mL}$ of $0.35 \%$ Agarose containing $5 \times 10^{3}$ B16F10Nex 2 cells and CaneCPI- 4 at $1 \mu \mathrm{M}$. Cultures were incubated for 2-3 weeks at $37^{\circ} \mathrm{C}$ in humidified incubator and the colonies were stained with $0.005 \%$ crystal violet for more than 1 hour and counted using an inverted microscope.

\section{In vivo tumor protection assay with sugarcane cystatins}

Six-to eight-week-old male C57BL/6 mice were injected subcutaneously on the right flank with a suspension containing $5 \times 10^{4}$ 
viable cells in $0.1 \mathrm{~mL}$ of serum-free RPMI medium in the presence of sugarcane cystatin at $1 \mu \mathrm{M}$. Alternatively, female mice were injected with melanoma cells at the same condition in the presence of $150 \mathrm{nM}$ of CaneCPI-4. Measurement of tumor growth was followed with a caliper every two days for 60 days and the survival of challenged animals was scored and statistically compared. The tumor volume was calculated using the formula: $\mathrm{V}=0.52 \times \mathrm{D} 1^{2} \times \mathrm{D} 3$, where $\mathrm{D} 1$ and $\mathrm{D} 3$ are the short and long tumor diameters, respectively. Maximal volumes of $3 \mathrm{~cm}^{3}$ were allowed before sacrifice. A group of control and treated animals were used for immunohistochemistry analysis. In this case, when tumors in the control group reached a diameter of $1 \mathrm{~cm}$, tumors were removed and fixed with formalin for immunohistochemical reaction and staining.
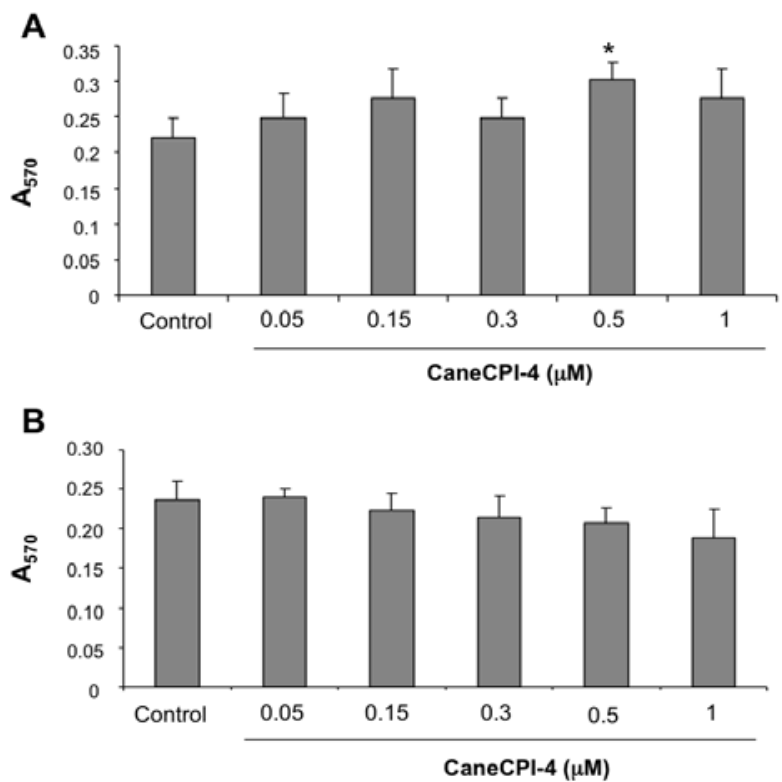

Figure 1: CaneCPI-4 is not toxic to B16F10-Nex2 and HUVEC cells. B16F10-Nex2 (A) or HUVEC (B) cells $\left(5 \times 10^{3}\right)$ were grown in 96-well plates, incubated for $24 \mathrm{~h}$ with CaneCPI-4 in RPMI medium without FCS and the cell viability was measured using MTT reagent. ${ }^{*} p<0.003$. Error bars, SD of triplicate determinations.

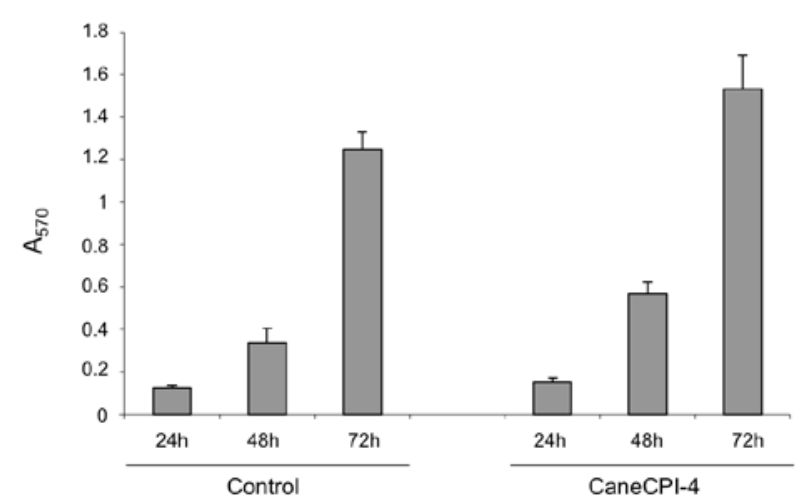

Figure 2: CaneCPI-4 does not modulate B16F10-Nex2 melanoma cell proliferation. B16F10-Nex2 melanoma cells $\left(10^{3}\right)$ were plated in 96-well plates and incubated with CaneCPI-4 at $1 \mu \mathrm{M}$ in complete RPMI medium. Cell viability was measured using MTT reagent. Error bars, SD of quadruplicate determinations.
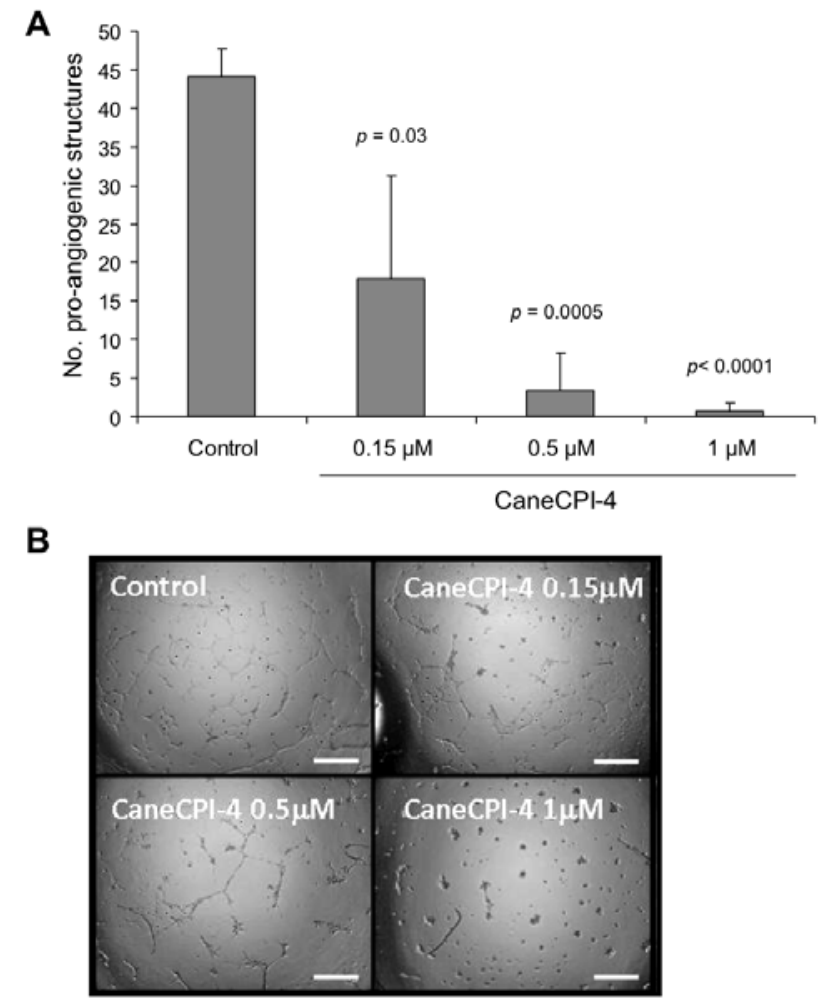

Figure 3: Sugarcane cystatin CaneCPI-4 inhibited endothelial cell angiogenesis on Matrigel in vitro. HUVEC cells $\left(5 \times 10^{3}\right)$ were plated on Matrigel supplemented with $0.5 \%$ FCS in the presence of CaneCPI- 4 at $0.15,0.5$ and $1 \mu \mathrm{M}$. The number of pro-angiogenic structures was counted after $18 \mathrm{~h} . p$ values in comparison with the control are shown. Error bars, SD of triplicate samples. A representative image with results of the three different treatments is shown. Scale bar $=100 \mu \mathrm{m}$.

To investigate the protective effect of recombinant sugarcane cystatin on the pulmonary metastatic melanoma model, C57Bl/6 mice were inoculated intravenously with $5 \times 10^{5}$ syngeneic B16F10-Nex2 viable cells in $0.1 \mathrm{~mL}$ for each mouse. Animals received on days 2, 4, 6, 8,10 and 12 after tumor cell challenge, i.p. doses of $1 \mu \mathrm{M}$ of CaneCPI- 4 in $100 \mu \mathrm{L}$ of RPMI, or PBS, at the same time period. After 15 days, the lungs were collected and inspected for metastatic colonization and the melanotic nodules were counted at $2 \mathrm{X}$ magnification. Data are reported as the mean number of tumor nodules \pm SE for six or more mice per group.

\section{Immunohistochemistry staining}

Immunohistochemistry analysis was performed as described previously. Briefly, the paraffin-embedded primary melanoma tissues were sectioned with a microtome, deparaffinized with xylene and rehydrated. Antigen retrieval was possible with citrate buffer $(0,01$ $\mathrm{M}, \mathrm{pH}$ 6.0) for 3 minutes under pressure and blocking of endogenous peroxidase with $6 \%$ hydrogen peroxide solution was performed. Tissue sections were incubated with polyclonal goat anti-mouse CD34 (C-18) (Santa Cruz Biotechnology, CA, USA) at $37^{\circ} \mathrm{C}$ for $30 \mathrm{~min}$ and then overnight at $4^{\circ} \mathrm{C}$. The slides were then incubated with the anti-goat secondary antibody conjugated with streptavidin-biotin-peroxidase complex (LSAB ${ }^{\mathrm{TM}}+$ kit; DAKO, Denmark) and the final reaction was developed DAB (3'-3-diaminobenzidine tetrahydrochloride, Sigma, 

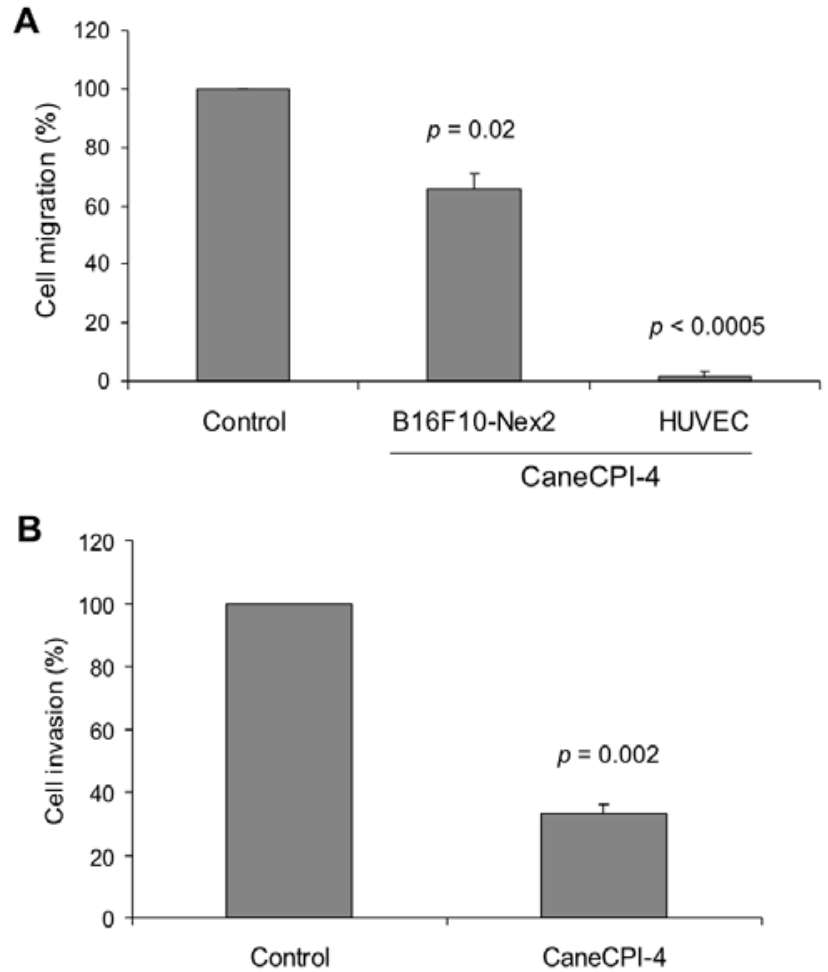

Figure 4: CaneCPI-4 inhibited cell migration and invasion in vitro. B16F10Nex2 melanoma cells and HUVECs at $10^{5}$ cells/well in $1 \mathrm{~mL}$ were seeded on 12 -well plates and after growing to form a confluent monolayer, one scratch wound was made. Cell migration (A) was determined by measuring the width of the wound at $\mathrm{Oh}$ and after $24 \mathrm{~h}$ incubation. For invasion assay, B16F10 Nex2 melanoma cells $\left(5 \times 10^{3}\right)$ were incubated on transwell units coated with Matrigel in the presence of CaneCPI-4 at $1 \mu \mathrm{M}$ for $24 \mathrm{~h}$. Invading cells were quantified by counting after crystal violet staining (B). Values are expressed in percentage comparing to control. $p$ values comparing to control are shown.

USA) chromogen substrate for $5 \mathrm{~min}$ at $37^{\circ} \mathrm{C}$. The sections were counterstained with Mayer's hematoxylin.

Microvessels were counted from three separated, most highly vascularized areas ("hot spots") as described previously [20]. The three areas were identified by scanning the stained tumor at X100 magnification and vessels were counted at X200 magnification using a Nikon digital site by an experienced pathologist. A square grid of $0.27 \mathrm{~mm}^{2}$ was used. Only vessels wholly within the area of the grid or touching the top or left-hand borders were counted.

\section{Statistical analysis}

The data values are means \pm SE. Statistical significance was determined by the Student's $t$ test. All experiments were repeated two or more times. Reproducible results were obtained and representative data are shown. The survival curves were analyzed by the Kaplan Meier and log rank significance tests. $p$-values $<0.05$ were considered significant.

\section{Results}

\section{Sugarcane cystatin CaneCPI-4 did not inhibit cell growth in vitro}

To study the effect of sugarcane cystatins on cell viability, B16F10Nex2 melanoma cells and HUVECs were plated on 96-wells plates in the presence of CaneCPI- 4 for 24h. Figures $1 \mathrm{~A}$ and $1 \mathrm{~B}$ show that sugarcane cystatin is not cytotoxic to melanoma and endothelial cells, respectively, when growing in a serum-free medium. CaneCPI- 4 had no effect either on melanoma or on endothelial cell viability in these serum-free conditions and in the concentrations used.

In addition, CaneCPI-4 had no effect on B16F10-Nex2 melanoma cell proliferation as can be seen in Figure 2, when sugarcane cystatin at $1 \mu \mathrm{M}$ was incubated with melanoma cells for 24,48 and $72 \mathrm{~h}$ in the presence of complete RPMI.

\section{CaneCPI-4 inhibited endothelial cell angiogenesis on Matrigel in vitro}

The effect of sugarcane cystatin on endothelial cell angiogenesis was tested using HUVEC cells plated on Matrigel in the presence of CaneCPI-4 (Figure 3). The growth of endothelial cells on Matrigel with $0.5 \%$ of FCS led to the formation of closed rings due to endothelial cell tube formation (pro-angiogenic structures) independent of any other factor. The addition of CaneCPI- 4 clearly inhibited the angiogenic process. The inhibitory effect of CaneCPI-4 on endothelial cell angiogenesis was dose-dependent and at $1 \mu \mathrm{M}$ it completely abolished endothelial cell sprouting.

\section{Inhibition of cell migration and invasion by CaneCPI-4}

The ability of sugarcane cystatin to modulate cell migration was tested using a monolayer wound-healing assay. B16F10-Nex2 and HUVEC cells were seeded and after complete cell confluence, one scratch wound was made in each well and CaneCPI- 4 was added for $24 \mathrm{~h}$. The cell migration through the gap was determined and the results are shown in Figure 4 A. CaneCPI- 4 was able to inhibit B16F10-Nex2 migration $25 \%$ and completely abolished HUVEC migration.

A transwell invasion assay using Matrigel was carried out to investigate the effect of recombinant sugarcane cystatin on the invasive capability of melanoma cells. B16F10-Nex2 cells were pre-incubated with CaneCPI-4 on transwell units coated with Matrigel and the invading cells were counted after $24 \mathrm{~h}$. The result can be visualized in Figure 4B. CaneCPI-4 inhibited significantly melanoma cell invasion by $60 \%$ compared to control.

\section{CaneCPI-4 inhibited primary melanoma growth, angiogenesis and melanoma lung metastasis}

To assess the effect of sugarcane cystatin on the tumor development in vivo, melanoma cells were injected subcutaneously $\left(5 \times 10^{4}\right.$ viable cells in $0.1 \mathrm{~mL}$ of serum-free RPMI medium) in male syngeneic mice together with CaneCPI- $4(0.16 \mu \mathrm{M})$, and the tumor growth (maximum of $3 \mathrm{~cm}^{3}$ ) and survival of challenged animals were measured. Animals (60\%) treated with CaneCPI-4 and challenged with murine melanoma cells showed prolonged survival (Figure 5A and B). The same experiment was carried out using female mice injected with melanoma cells and treated with CaneCPI- $4(0.15 \mu \mathrm{M})$. Curiously, none of the treated-mice allowed tumor development after challenge (Figure $5 \mathrm{C}$ and D).

CD34 is an endothelial antigen used to determine the number of microvessels hence the degree of angiogenesis in vivo. Upon analyzing the immunohistochemical staining, the number or microvessels of the untreated group was 2-fold higher than that of the CaneCPI-4-treated animals (Figure 6A and $\mathrm{B}$ ), indicating that angiogenesis in vivo was effectively inhibited by CaneCPI- 4 . 
A

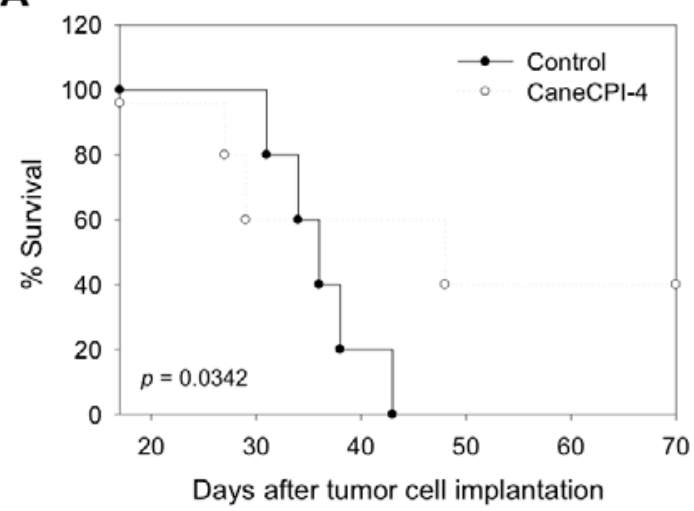

B

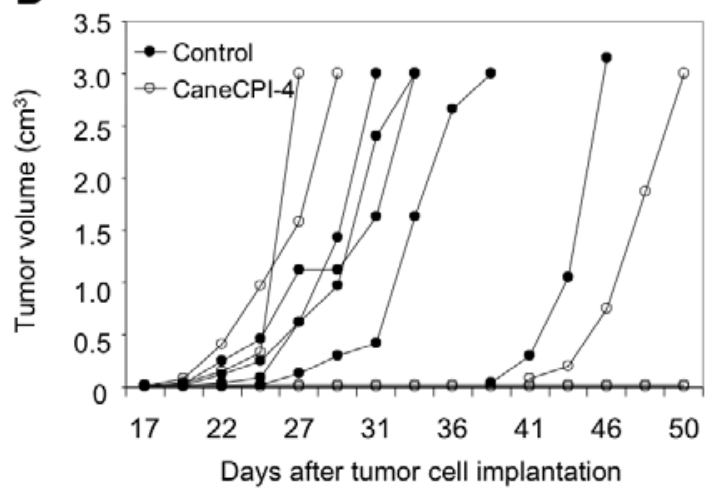

C

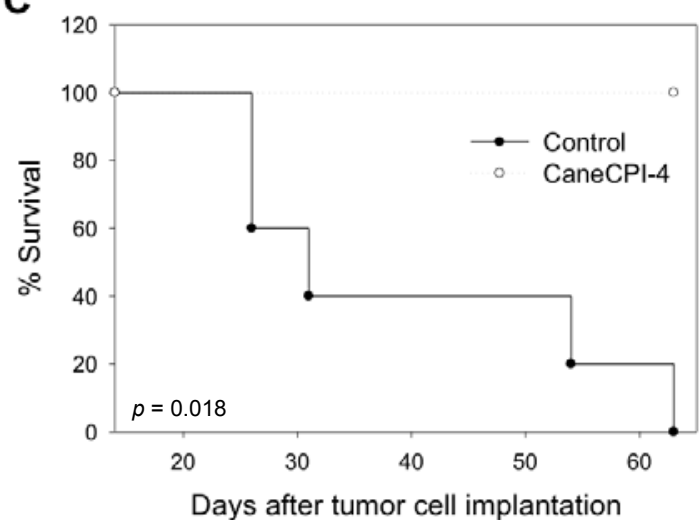

D

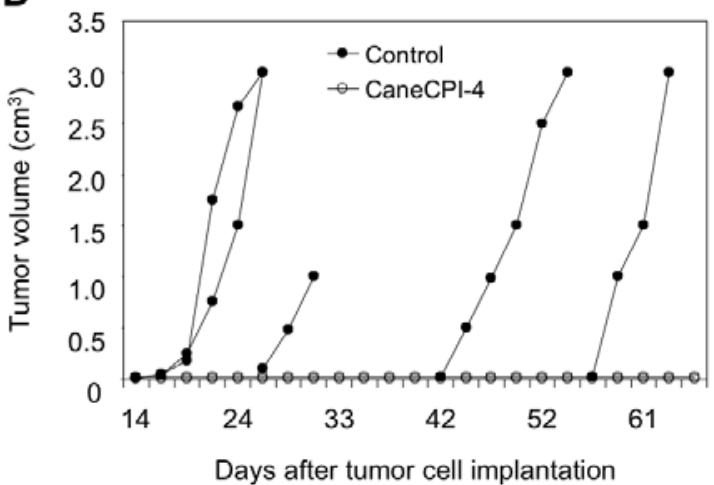

Figure 5: CaneCPI-4 reduces tumor cell development in vivo. Tumor cells $\left(5 \times 10^{4}\right)$ were injected subcutaneously in C57BI/6 male (A and B) or female (C and D) mice in the presence of Cane-CPI-4 (open circles), or PBS (control, closed circle). The tumor volume was measured every 2-3 days and the animals were sacrificed at a maximum volume of $3 \mathrm{~cm}^{3}$. (A and C) Survival plots. (B and D) Tumor volume of individual animals. Statistical analysis of survivals was performed using Kaplan-Meier test and $p$ value comparing to control is shown in the Figure. Statistical analysis of survivals was performed using Kaplan-Meier test and $p$ value in comparison with the control is shown.

A

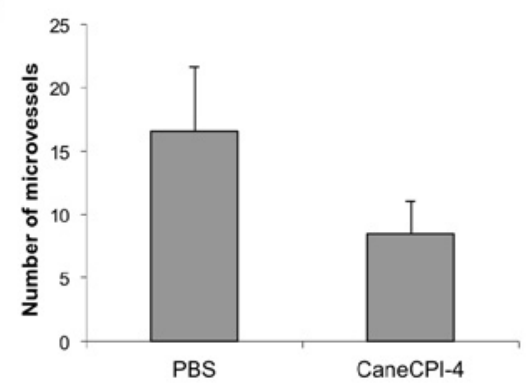

B

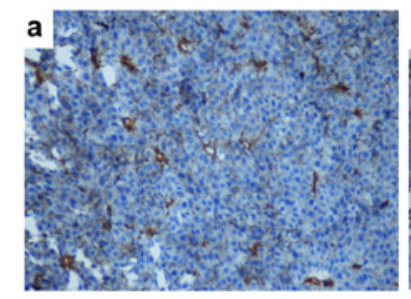

PBS

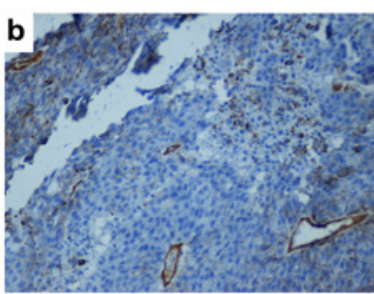

CaneCPI-4

Figure 6: Tumor angiogenesis evaluation in CaneCPI-4-treated animals. B16F10-Nex2 cells $\left(5 \times 10^{4}\right)$ were injected subcutaneously in C57BI/6 male in the presence of Cane-CPI-4 or PBS. When tumors in the control group reached a diameter of $1 \mathrm{~cm}$, tumors were removed and fixed in formalin for immunohistochemistry analysis of angiogenesis by antibodies to CD34. (A) Quantification of microvessels. Error bars, SD of 5 animals. (B) Immunohistochemical analysis of CD34 expression in tumor tissue. (a) PBS control and (b) mice treated with CaneCPI-4 at $1 \mu \mathrm{M}$. 
Treatment of mice challenged intravenously with B16F10-Nex2 cells was also investigated using sugarcane cystatins. Mice were injected intravenously with $5 \times 10^{5}$ tumor cells in $0.1 \mathrm{~mL}$ of serum-free RPMI and treated on days $2,4,6,8,10$ and 12 with CaneCPI- 4 at $1 \mu \mathrm{M} /$ injection in $100 \mu \mathrm{L}$ of PBS. In Figure 7A it is shown that animals treated with sugarcane cystatin exhibited nodules than animals treated with PBS. Lungs of animals treated with CaneCPI- 4 and PBS can be visualized in Figure 7B.

\section{Sugarcane cystatin partially inhibited B16F10-Nex2 anchorage-independent growth}

Melanoma cell line was cultivated in soft agar to verify the effect of sugarcane cystatin in the anchorage-independent growth. CaneCPI-4 effectively inhibited the B16F10-Nex2 cell anchorage-independent growth approximately $45 \%$ (Figure 8 ).

\section{Discussion}

We have examined the effect of recombinant sugarcane cystatin CaneCPI-4 on tumor development in vivo and on cell migration, invasion and proliferation in vitro. Cystatins are natural cysteine protease inhibitors and its primary function is to regulate cathepsins released from lysosomes. A wide variety of cysteine cathepsins is

\section{A}

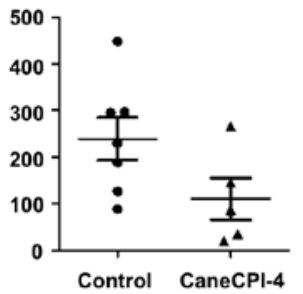

B

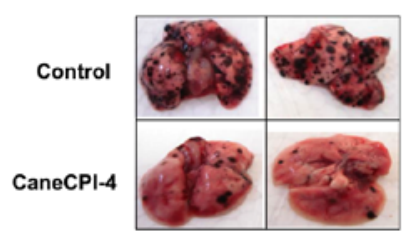

Figure 7: Effect of sugarcane cystatin in the lung colonization after implantation of B16F10-Nex2 melanoma cells. C57BI/ 6 mice ( $n=7$, control group; $n=5$, treated-group) were injected intravenously with $5 \times 10^{5}$ B16F10-Nex2 melanoma cells. CaneCPI-4 $(1 \mu \mathrm{M}, \boldsymbol{\Delta})$ was administered intraperitoneally $(100 \mu \mathrm{L})$ on days 2, 4, 6, 8, 10 and 12 after tumor cell challenge. Control mice received PBS (control, •) at the same time period. Lungs were collected 15 days after tumor challenge and the nodules were counted. (a) Total number of lung metastases. Number of lung lesions \pm SE. Two independent experiments were performed. $p=0.0347$, CaneCPI-4 vs control. (b) Lungs from B16-bearing mice treated with PBS and CaneCPI-4.

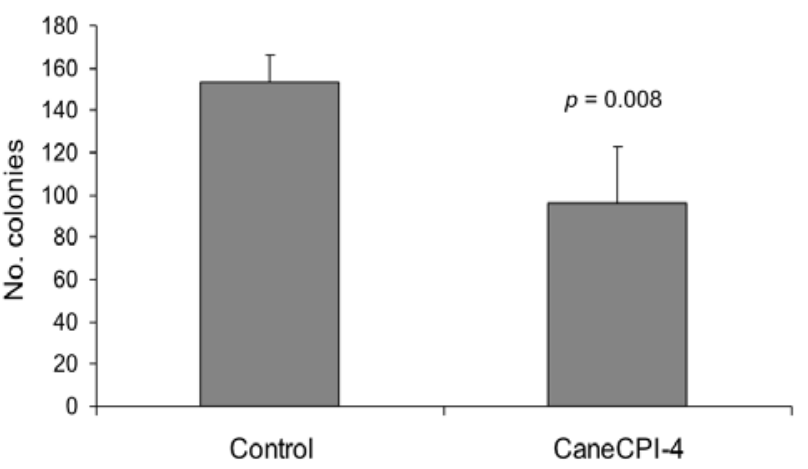

Figure 8: Anchorage-independent colony growth in soft agar in the presence of sugarcane cystatin. B16F10-Nex2 cells $\left(5 \times 10^{3}\right)$ were cultivated in soft agar in 12-well plates as described previously in the presence of CaneCPI-4 at $1 \mu \mathrm{M}$. After 2-3 weeks, the colonies were stained and counted. $p$ values in comparison to the control are shown. known to be expressed in tumor cells and tumor-associated cells and such enzymes contribute for cancer progression [6]. In tumor cells, cathepsins are upregulated, distributed in endosomal and lysosomal vesicles, on the cell membrane, being also secreted and recycled back onto the cell. Extracellular cathepsins are able to degrade extracellular matrix proteins such as laminin [21,22], type IV collagen [21], tenascin C [23] and cell-adhesion proteins like E-cadherin [24], contributing to tumor cell detachment and invasion. Many reports have indicated an increased cathepsin to cystatin ratio in different tumors compared to normal tissues [13]. Therefore, cathepsin inhibitors could be effective as anti-cancer agents.

The sugarcane cystatin CaneCPI-4 was not toxic to both melanoma and endothelial cells growing in vitro, but inhibited endothelial cell sprouting in vitro on Matrigel in a dose-dependent manner. Endothelial cells rapidly form capillary-like structures in vitro when plated on top of a reconstituted basement membrane extracellular matrix, such as Matrigel. The differentiation process involves several steps in blood vessel formation, including cell adhesion, migration, alignment, protease secretion, and tubule formation [25]. To verify the ability of sugarcane cystatin to modulate endothelial cell migration, a monolayer wound repairing assay was used. CaneCPI-4 $(1 \mu \mathrm{M})$ inhibited melanoma cell migration and completely abolished HUVEC migration. The effect of CaneCPI-4 on endothelial cell migration was significantly more pronounced than that on melanoma cell migration.

Anti-angiogenic therapy represents a recognized strategy for cancer treatment [26]. Angiogenesis is a fundamental process in tumor initiation, development and metastasis. To investigate the effect of sugarcane cystatins on angiogenesis-dependent tumor development in vivo, C57B16 mice were injected subcutaneously with B16F10-Nex2 cells in the presence of non-toxic concentrations of CaneCPI-4. CaneCPI-4 was able to prolong the survival of mice challenged with tumor cells. The reduced angiogenesis in treated animals was confirmed by CD34 staining in the growing tumor.

CaneCPI-4 was also used to treat animals injected intravenously with B16F10-Nex2 melanoma cells and also in this metastatic model there was inhibition of pulmonary nodule formation. In a population of tumor cells, the metastatic phenotype is played by a small number of selected tumor cells that have survived in the blood circulation, are trapped in the capillary beds by adhering either to capillary endothelial cells or to subendothelial basement membrane that may be exposed [27]. Extravasations may involve mechanisms similar to those used during invasion. CaneCPI-4 efficiently inhibited melanoma cell invasion in vitro using a Transwell invasion assay.

It is possible that sugarcane cystatin, considering our assay condition, may act on cysteine proteases essential for implantation and early development of the metastatic tumor. Proteases target a great variety of substrates that inhibit or stimulate cancer progression, such as growth factors, cell death receptors, cystatin-C, galectin, procollagen, and other proteases [28]. Besides, proteases can cleave cell-adhesion molecules, such as epithelial E-cadherin, leading to the disruption of cell-cell junctions [5,29]. These different mechanisms of invasion modulated by proteases are not mutually exclusive; they act in concert to promote cancer cell spread [30]. The pharmacological inhibition or genetically ablation of these protease families promotes reduction in cancer cell invasion [24,31,32]. CaneCPI-4 inhibited tumor cell invasion in vitro in a Matrigel invasion assay and also reduced lung metastasis as natural cysteine protease inhibitors. Besides, CaneCPI-4 partially inhibited the melanoma cell anchorage-independent growth. 
The anchorage independent-survival is the ability of cancer cells to proliferate without adhesion to extracellular matrix and is fundamental in the invasion process and metastasis.

Gianotti et al. [17] demonstrated that CaneCPI-4 have different inhibitory potencies when acting on human cathepsins B and L. CaneCPI-4 effectively inhibited the activity of cathepsin B, with a very low $K_{\mathrm{i}}$ of $0.83 \mathrm{nM}$ [17]. We also tested the inhibitory effect of CaneCPI- 4 against cathepsins $\mathrm{K}$, and $\mathrm{S}$ and observed low $K_{\mathrm{i}}$ values in the $\mathrm{nM}$ order $(2.90 \mathrm{nM}$ and $4.38 \mathrm{nM}$, respectively), suggesting that this cystatin can be acting in multiple ways.

The role of cathepsins in angiogenesis modulation has been studied in a wide variety of tumor models. Im et al. [33] showed that cathepsin $\mathrm{B}$ can act as a regulator of the concentration of angiomodulators at the level of the endothelium. Besides, cathepsin B appears to contribute significantly to melanoma cell spreading and metastatic potential [34]. In the RIP1-Tag2 model, cathepsin S is required for angiogenesis and is associated with the pathobiology of tumor growth [35].

\section{Conclusions}

Presently, we demonstrate the potent inhibitory activity of CaneCPI-4 against melanoma cells in vitro and in vivo. New therapeutic strategies focusing on cysteine protease inhibitors are promising, with the possible application of this phytocystatin in anti-cancer strategies.

\section{Acknowledgements}

This work was supported by Fundação de Amparo à Pesquisa do Estado de São Paulo (FAPESP), Brazil. LRT and AKC are research fellows from the CNPq.

\section{References}

1. Hanahan D, Weinberg RA (2000) The hallmarks of cancer. Cell 100: 57-70.

2. Folkman J (2002) Role of angiogenesis in tumor growth and metastasis. Semin Oncol 6: 15-18.

3. Bergers G, Benjamin LE (2003) Tumorigenesis and the angiogenic switch. Nat Rev Cancer 3: 401-410.

4. Whitelock JM, Murdoch AD, lozzo RV, Underwood PA (1996) The degradation of human endothelial cell-derived perlecan and release of bound basic fibroblast growth factor by stromelysin, collagenase, plasmin, and heparanases. J Bio Chem 271: 10079-10086.

5. Gocheva V, Joyce JA (2007) Cysteine cathepsins and the cutting edge of cancer invasion. Cell Cycle 6: 60-64.

6. Mohamed MM, Sloane BF (2006) Cysteine cathepsins: multifunctional enzymes in cancer. Nat Rev Cancer 6: 764-775.

7. Kruszewski WJ, Rzepko R, Wojtacki J, Skokowski J, Kopacz A, et al. (2004) Overexpression of cathepsin B correlates with angiogenesis in colon adenocarcinoma. Neoplasma 51: 38-43.

8. Yanamandra N, Gumidyala KV, Waldron KG, Gujrati M, Olivero WC, et al. (2004) Blockade of cathepsin B expression in human glioblastoma cells is associated with suppression of angiogenesis. Oncogene 23: 2224-2230.

9. Yang Z, Cox JL (2007) Cathepsin L increases invasion and migration of B16 melanoma. Cancer Cell Int 7: 8-16.

10. Freitas ZF, Rodrigues EG, Oliveira V, Carmona AK, Travassos LR (2004) Melanoma heterogeneity: differential, invasive, metastatic properties and profiles of cathepsin B, D and L activities in subclones of the B16F10-NEX2 cell line. Melanoma Res 14: 333-344.

11. Quintanilla-Dieck MJ, Codriansky K, Keady M, Bhawan J, Rünger TM (2008) Cathepsin K in melanoma invasion. J Invest Dermatol 128: 2281-2288.

12. Turk B, Turk D, Salvesen GS (2002) Regulating cysteine protease activity: essential role of protease inhibitors as guardians and regulators. Curr Pharm Des 8: 1623-1637.

13. Cox JL (2009) Cystatins and cancer. Front Biosci 14: 463-474.
14. Zajc I, Sever N, Bervar A, Lah TT (2002) Expression of cysteine peptidase cathepsin $L$ and its inhibitors stefins $A$ and $B$ in relation to tumorigenicity of breast cancer cell lines. Cancer Lett 187: 185-190.

15. Colella R, Casey SF (2003) Decreased activity of cathepsins L + B and decreased invasive ability of PC3 prostate cancer cells. Biotech Histochem 78 101-108.

16. Nishikawa H, Ozaki Y, Nakanishi T, Blomgren K, Tada T, et al. (2004) The role of cathepsin $B$ and cystatin $C$ in the mechanisms of invasion by ovarian cancer Gynecol Oncol 92: 881-886.

17. Gianotti A, Sommer CA, Carmona AK, Henrique-Silva F (2008) Inhibitory effect of the sugarcane cystatin CaneCPI-4 on cathepsins $B$ and $L$ and human breast cancer cell invasion. Biol Chem 389: 447-453.

18. Gianotti A, Rios WM, Soares-Costa A, Nogaroto V, Carmona AK, et al. (2006) Recombinant expression, purification, and functional analysis of two nove cystatins from sugarcane (Saccharum officinarum). Protein Expr Purif 47: 483489

19. Paschoalin T, Carmona AK, Rodrigues EG, Oliveira V, Monteiro HP, et al (2007) Characterization of thimet oligopeptidase and neurolysin activities in B16F10-Nex2 tumor cells and their involvement in angiogenesis and tumor growth. Mol Cancer 6: 44-58.

20. Foss AJ, Alexander RA, Jefferies LW, Hungerford JL, Harris AL, et al. (1996) Microvessel count predicts survival in uveal melanoma. Cancer Res 56: 2900 2903

21. Buck MR, Karustis DG, Day NA, Honn KV, Sloane BF (1992) Degradation of extracellular-matrix proteins by human cathepsin B from normal and tumour tissues. Biochem J 282: 273-278.

22. Ishidoh K, Kominami E (1995) Procathepsin L degrades extracellular matrix proteins in the presence of glycosaminoglycans in vitro. Biochem Biophys Res Commun 217: 624-631.

23. Mai J, Sameni M, Mikkelsen T, Sloane BF (2002) Degradation of extracellular matrix protein tenascin-C by cathepsin $B$ : an interaction involved in the progression of gliomas. Biol Chem 383: 1407-1413.

24. Gocheva V, Zeng W, Ke D, Klimstra D, Reinheckel T, et al. (2006) Distinct roles for cysteine cathepsin genes in multistage tumorigenesis. Genes Dev 20 543-556.

25. Arnaoutova I, George J, Kleinman HK, Benton G (2009) The endothelial cell tube formation assay on basement membrane turns 20: state of the science and the art. Angiogenesis 12: 267-274.

26. Eichhorn ME, Kleespies A, Angele MK, Jauch KW, Bruns CJ (2007) Angiogenesis in cancer: molecular mechanisms, clinical impact. Langenbecks Arch Surg 392: 371-379.

27. Fidler IJ (2003) The pathogenesis of cancer metastasis: the 'seed and soil' hypothesis revisited. Nat Rev Cancer 3: 453-458.

28. Flores-Reséndiz D, Castellanos-Juárez E, Benítez-Bribiesca L (2009) Proteases in cancer progression. Gac Med Mex 145:131-142.

29. Masterson J, O'Dea S (2007) Posttranslational truncation of E-cadherin and significance for tumour progression. Cells Tissues Organs 185: 175-179.

30. Joyce JA, Pollard JW (2009) Microenvironmental regulation of metastasis. Nat Rev Cancer 9: 239-252.

31. Egeblad M, Werb Z (2002) New functions for the matrix metalloproteinases in cancer progression. Nat Rev Cancer 2: 161-174.

32. Joyce JA, Baruch A, Chehade K, Meyer-Morse N, Giraudo E, et al. (2004) Cathepsin cysteine proteases are effectors of invasive growth and angiogenesis during multistage tumorigenesis. Cancer Cell 5: 443-453.

33. Im E, Venkatakrishnan A, Kazlauskas A (2005) Cathepsin B regulates the intrinsic angiogenic threshold of endothelial cells. Mol Biol Cell 16: 3488-3500.

34. Matarrese P, Ascione B, Ciarlo L, Vona R, Leonetti C, et al. (2010) Cathepsin $B$ inhibition interferes with metastatic potential of human melanoma: an in vitro and in vivo study. Molecular Cancer 9: 207-221.

35. Wang B, Sun J, Kitamoto S, Yang M, Grubb A, et al. (2006) Cathepsin S controls angiogenesis and tumor growth via matrix-derived angiogenic factors. J Biol Chem 281: 6020-6029. 